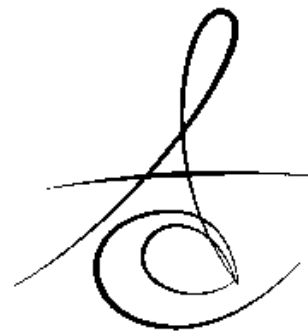

Makale Kodu/Artıcle code: 2488

Makale Gönderilme tarihi: 09.12 .2015

Kabul Tarihi: 07.04.2016

\title{
FARKLI GÜDÜK MATERYALLERİ, SAKLAMA ORTAMI VE SİMANIN ZİRKON ALT YAPILARININ KIRILMA DİRENCİ ÜZERÍNDE ETKİSİ ${ }^{\neq}$
}

\section{THE EFFECT OF DIFFERENT DIE MATERIAL, CEMENT AND STORAGE MEDIA ON FRACTURE STRENGTH OF ZIRCON SUBSTRUCTURAL CERAMIC ${ }^{\ddagger}$}

\author{
Arş. Gör. Dt. Özlem ÖZBAYRAM* \\ Prof. Dr. Nuran YANIKOĞLU*
}

Yrd. Doç. Dr. Nurdan POLAT SAĞSÖZ*

\section{öz}

Amaç: Bu çalışmanın amacı: zirkon alt yapıların kırılma direnci üzerinde; farklı elastik modülüne sahip güdük materyallerinin, simanın ve saklama ortamının etkisini değerlendirmektir.

Gereç ve Yöntem: Çalışmada güdük alt yapı materyali olarak dentin (1. premolar diş), Cr-Co ve kompozit resin kullanıldı. Dişler $1 \mathrm{~mm}$ genişliğinde shoulder basamak bitiş çizgisiyle, serviko-okluzal olarak 12 derecelik taper açısıyla prepare edildi. Silikon esaslı ölçü maddesi kullanılarak dentin güdüklerin ölçüleri alındı ve dublike güdükler $\mathrm{Cr}$-Co metal ve ışıkla sertleşen kompozit materyalinden elde edildi. Üç farklı materyalden 60 güdük hazırlandı. Güdükler üzerine zirkon alt yapılar hazırlandı. Her bir materyalden hazırlanan güdükler iki alt gruba ayrıldı. Zirkon alt yapılar birinci gruptaki güdükler üzerine geleneksel polikarboksilat siman ile yapıştırılırken, ikinci gruptakiler üzerine siman konulmadan oturtuldu. Test öncesi örnekler $37{ }^{\circ} \mathrm{C}$ de bir hafta süreyle distile su ve kolada bekletildi. Kırılma dayanımı testi Universal test makinesi ile yapıldı. 0,5 mm/dk. başlık hızı ile alt yapı kırılana kadar sıkıştırma yükü uygulandı. Elde edilen değerler Newton(N) olarak kaydedildi. Çalışma verileri değerlendirilirken gruplar arası ortalamaların karşılaştırılmasında Çift Yönlü Varyans Analizi testi ve Post Hoc çoklu karşılaştırma testlerinden LSD testi kullanıldı. $p<0,05$ için sonuçlar istatistiksel olarak anlamlı kabul edildi.

Bulgular: Güdük materyallerinin kırıma dayanımı değerleri arasındaki fark istatistiksel olarak anlamlı bulundu $(p<0,05)$. En yüksek kırılma direnci değeri $(5790,5 \mathrm{~N})$ dentin güdük materyalleri üzerindeki zirkon alt yapılarında bulundu. Bunu metal ve kompozit güdük üzerindeki alt yapılar takip etti $(4563,3 \mathrm{~N} ; 3909,0 \mathrm{~N})$. Simanlı ve simanSIz gruplar arasındaki fark istatistiksel olarak anlamlı bulundu $(p<0,001)$. Farklı solüsyonlara konulmuş gruplar arasındaki değerlerde ise istatistiksel olarak anlamlı bir farklılık bulunmadı $(p>0,05)$.

Sonuç: Güdük çeşidine göre Zirkon alt yapı kırılma dayanımı değeri en yüksek dentinde, en düşük değer ise kompozitte bulundu. Bütün güdük materyalleri üzerindeki zirkon alt yapı kırıma direnci simanlı gruplarda simansız gruplardan daha yüksek bulundu. Farklı solüsyonlara konulmuş alt yapılarda kırılma dayanımı açısından herhangi bir farklılık bulunmadı.

Anahtar kelimeler: Güdük materyalleri; Zirkon; kırıma dayanımı

* Atatürk Üniversitesi Diş Hekimliği Fakültesi Protetik Diş Tedavisi AD.

\# Bu makale 5.Uluslararası Türk Prostodonti ve Implantoloji Derneği Bilimsel Sempozyumu'nda poster olarak sunulmuştur. 18-20 Mart 2016/Erzurum-Türkiye

\section{ABSTRACT}

Aim: The aim of this study was to evaluate the effect of different elastic modulus die material, cement and storage on the fracture resistance of zirconia substructure.

Material and Method: As a die infrastructure material, dentin( 40 non-carious upper 1st premolar), $\mathrm{Cr}-\mathrm{Co}$ and composite resin was used. The teeth was prepared by the cervico-occlusal taper angle and shoulder step finish line. The measurement was taken of dentin die using a silicone-based impression material and dublicated dies was obtain from $\mathrm{Cr}$-Co metal and light-curing composite material. 60 dies was prepared three different material. Zirconia substructure was prepared on the dies. Prepared dies was divided into two groups. Zirconia substructure was cemented with conventional polycarboxylate cement on the first group and second group was non-cemented. Before testing samples were incubated at $37^{\circ} \mathrm{C}$ in distilled water and coke for a week. Fracture resistance test was performed by Universal testing machine. Compression load was applied with $0.5 \mathrm{~mm} / \mathrm{dk}$ head speed until the substructure was broken. The obtained values was recorded in Newton $(\mathrm{N})$. While the data were analyzed, Two wat ANOVA test and LSD test that one of Post Hoc multipl comparison tests were used. $p<0.05$ was considered statistically significant for results.

Results: Highest fracture resistance value (5790.5 N) were found in zirconium substructure materials on the dental die. Substructure on the composite metal die were followed $(4563.3 \mathrm{~N} 3909.0 \mathrm{~N})$ the dental die. The difference between fracture resistance of die material was statistically significant. $(p<0,05)$ The differences between cemented and non-cemented group was statistically significant. $(p<0.001)$ The difference between different solution groups was no statistically significant. ( $p>0.05)$

Conclusion: Acording to die material, the highest fracture resistance value was found in dentin and the lowest value was found in composite. The fracture resistances value of cemented group on the zirconia substructure materials were higher than non-cemented groups. There were no differences in fracture resistance of substructure put in different solution.

Keywords: Die materials; Zirconia; fracture resistance 


\section{GİRİŞ}

Metal seramik kuronlar 40 yılı aşkın süredir kullanılan güçlü ve fonksiyonel restorasyonlardır. ${ }^{1}$ Estetiğe karşı artan talep metal içermeyen doğal diş rengine yakın materyal bulma çalışmalarına yönlendirmiştir. Bu amaçla kullanılmaya başlanan tam seramik restorasyonların çevre dokularla olan biyouyumluluğu ${ }^{2}$, doğal dişe yakın estetiği, aşınma direnci ve renk stabilitesi ${ }^{3}$ hastaların tercih etmesinde teşvik edici niteliklerdir. Tam seramik restorasyonlar içerisinde ideal alt yapı malzemesi arayışında gelinen son nokta yitriyum tetragonal zirkonya polikristal esaslı seramiklerdir. ${ }^{4,5}$ Zirkonyanın istenmeyen faz değişimini engelleyerek oda sıcaklığında tetragonal fazda kalmasını sağlamak ve genleşmesini önlemek için yapısına \%3 mol yitriyum oksit eklenmektedir. ${ }^{6}$ Zirkonyum seramikler biyouyumluluğu, estetik olması ve diğer birçok seramik materyalden yüksek kırılma dayanımı, düşük plak birikimi gibi özellikleri sayesinde diş hekimliği alanında alt yapı materyali olarak sıklıkla tercih edilmektedir. ${ }^{7-9}$ Son zamanlarda, bilgisayar destekli tasarım/bilgisayar destekli üretim (CAD/CAM) in tanıtımıyla sinterleme ve millemeden sonra zirkonlarda meydana gelen büzülme gibi dezavantajların üstesinden gelinmiş ve zirkonyum restorasyonların uyumunu geliştirmeye yardımcı olmuştur. ${ }^{10}$ Bilgisayar destekli tasarım/bilgisayar destekli üretim (CAD/CAM) sistemleri 1980'li yılların başlarında diş hekimliğinde kullanılmaya başlanmıştır. Son yıllarda hızla önem kazanmış ve popüler hale gelmiştir. Böylece yüksek performanslı malzemelerin şekillenmesini sağlamıştır. ${ }^{11}$ CAD/CAM teknolojisi daha kısa sürede ve daha yüksek kalitede üretimi sağlar. Teknikteki hataları minimuma indirir ve klasik çok aşamalı indirekt restorasyon üretimindeki çapraz kontaminasyon, enfeksiyon tehlikesini azaltır. Ancak maliyeti biraz yüksektir. ${ }^{12}$

Seramik restorasyonların ana problemlerinden biri de meydana gelen kırıklardır. ${ }^{13} \mathrm{Bu}$ durum tam seramik kuronlarda klinik başarıyı etkileyen önemli bir faktördür. ${ }^{14}$ Dayanım (strength), kırılgan materyallerin performansını etkileyen önemli bir özelliktir. Bir materyalde plastik deformasyon ya da kırık oluşması için gereken stres miktarıdır. Dayanım değeri materyalin yüzeyindeki çatlakların, defektlerin ve suyun varlığından etkilenir. ${ }^{15}$ Kırılma direnci restorasyonun kalınlığı, yüzey pürüzlülüğü, dişin kesim dizaynı, yapıştırıcı simanın özellikleri, destekleyici alt yapının elastik modülüne bağlıdır. ${ }^{16-18}$ Tam seramik restorasyonların ağız ortamında uzun dönem başarıyla hizmet edebilmeleri seramik, yapıştırma ajanı ve diş yapıları arasındaki bağlanmanın başarısına bağlıdır.

Doğal dişleri çekim sonrası saklama süresi, hastanın yaşı ve dişlerde görülen anatomik farklılıklardan dolayı in vitro çalışmalarda kullanımlarında standardizasyonu sağlamak zordur. ${ }^{19}$ Ayrıca in vitro çalışmalardaki kırılma dayanımı testlerinde klinik koşulları doğru bir şekilde yansıtmak için dentinin elastik modülüne yakın güdük materyalleri kullanılmalıdır. Tam seramik kuronların kırılma direncinin değerlendirildiği birçok çalışmada güdük materyali olarak metal, pirinç, epoksi rezin ve akrilik rezin kullanılmıştır. ${ }^{20,21}$ Tam seramik kuronların kırılma direncini arttırmada güdük materyalinin artan elastik modülünün önemli bir etkisinin olduğu bulunmuştur. ${ }^{22}$

Adeziv simantasyon tam seramik kuronlar için yüksek marjinal uyum sağlamakta, tutuculuğu arttırmaktadır. Ancak zirkonyum asitlenemeyen bir materyal olduğu için geleneksel simanlar adeziv simanlara önemli bir alternatiftir. ${ }^{23} \mathrm{Bu}$ yüzden zirkonyum restorasyonların simantasyonu polikarboksilat siman ya da modifiye cam iyonomer simanlarla yapılabilir.

Bu çalışmanın amacı: zirkon alt yapıların kırıma direnci üzerinde; farklı elastik modülüne sahip güdük materyallerinin, simanın ve saklama ortamının etkisini değerlendirmektir. Hipotezimiz; zirkonyum alt yapıların kırılma direnci üzerinde simanın, asidik ortamın ve güdük materyallerinin etkili olacağı yönündedir. Özellikle $\mathrm{Ni}-\mathrm{Cr}$ güdüklerin üzerinde ve simante edildiğinde daha yüksek kırılma direnci görüleceğini tahmin etmekteyiz.

\section{MATERYAL VE METOT}

$\mathrm{Bu}$ çalışmada güdük alt yapı materyali olarak dentin (1.premolar diş), Cr-Co ve kompozit kullanıldı. Çekilmiş dişlerin üzerinden diş taşları temizlendi ve yumuşak dokular çıkartıldı. Dişler \% 0,1 timol çözeltisi içinde muhafaza edildi. Dişlerin preparasyonları üreticilerin önerileri doğrultusunda zirkon alt yapılı seramikler için hazırlandı. Standardizasyon için aynı araştırmacı tarafından preparasyonlar yapıldı. 
Dişler $1 \mathrm{~mm}$ genişliğinde shoulder basamak bitiş çizgisiyle serviko-okluzal olarak 12 derecelik taper açısıyla prepare edildi (Şekil 1). CAD/CAM cihazının ağız içi kamerasıyla prepare edilen dişten görüntüler alındı. Elde edilen görüntüler üzerinde taper açısının doğruluğu kontrol edildi. Silikon esaslı ölçü maddesi (Elite HD; Zhermack, İtalya) kullanılarak dentin güdüklerin ölçüleri alındı ve dublike güdükler $\mathrm{Cr}$-Co metal (Cast-n Dental Seramik Alloy, Dentinex, Hagen, Almanya) ve ışıkla sertleşen kompozit materyalinden (Built-it; Pentron/West Collins Clinical/Amerika) elde edildi. Üç farklı materyalden 20'şer tane olmak üzere toplamda 60 güdük hazırlandı $(n=5)$. Örnekler sabitlenmeleri için kimyasal olarak polimerize olan akrilik rezinin ( Imıcryl; Konya, Türkiye) içine gömüldü. Güdükler üzerine hazırlanan zirkon alt yapıların (Katana; Noritake Dental, Aichi, Japonya) standardizasyonu sağlamak için şekillendirme işleminde CAD/CAM cihazı (Yenadent DC 40,Yenadent Ltd, İstanbul, Turkey) kullanıldı. Örnekler oda sıcaklığındaki fırına (Protherm; Haryana, India) alındı. Fırının sıcaklığı 2 saatte $1100^{\circ} \mathrm{C}^{\prime}$ den $1375{ }^{\circ} \mathrm{C}$ ye 1 saatte gelip $1375{ }^{\circ} \mathrm{C}$ de 2 saat bekletildi. Fırının sıcaklığı 3 saatte $1375{ }^{\circ} \mathrm{C}$ den oda sıcaklığına soğuduğunda sinterizasyon işlemi tamamlandı. Sinterizasyon sonrası zirkon alt yapıların kalınlığı üretici talimatlarına göre $0,5 \mathrm{~mm}$ olarak hazırlandı.

Her bir materyalden hazırlanan güdükler iki alt gruba ayrıldı. Zirkonyum alt yapılar birinci gruptaki güdüklerin üzerine geleneksel siman polikarboksilat siman (Durelon;3M ESPE, Almanya) ile yapıştırılırken, ikinci gruptakiler üzerine siman konulmadan oturtuldu. Toz likit oranı ayarlanıp, 30-40 sn içinde hızlıca karıştırıldı. Siman, alt yapının her yüzeyine gelecek şekilde konuldu. Alt yapı güdükler üzerine parmak basıncıyla yerleştirildi ve daha sonra $22 \mathrm{~N}^{\prime}$ luk statik yük yükleme cihazıyla 6 dakika boyunca uygulandı. Simanın lastiksi kıvamı geçtikten sonra kenarlardan taşan siman artıkları uzaklaştırıldı. Test öncesi örnekler $37^{\circ} \mathrm{C}$ de bir hafta süreyle distile su ve kolada (Coca Cola, ABD) bekletildi.

Kırılma dayanımı testi Universal test makinesi (Model 2519-106; Instron Corp, USA) ile yapıldı (Şekil 2). Örnekler universal test cihazındaki yuvaya olası rotasyonları engellemek amacıyla sabitlendi. Cihazın hareketli üst bölümüne monte edilen $4 \mathrm{~mm}$ çaplı çelik küre uç ile anatomik forma uygun olarak hazırlanan alt yapının santral fossa ve tüberkül eğimleri üzerinden dişin uzun ekseni boyunca yükleme yapıldı. ${ }^{24,25} 0,5$ $\mathrm{mm} / \mathrm{dk}$. başlık hızı ile alt yapı kırılana kadar sıkıştırma yükü uygulandı. Elde edilen değerler Newton(N) olarak kaydedildi.
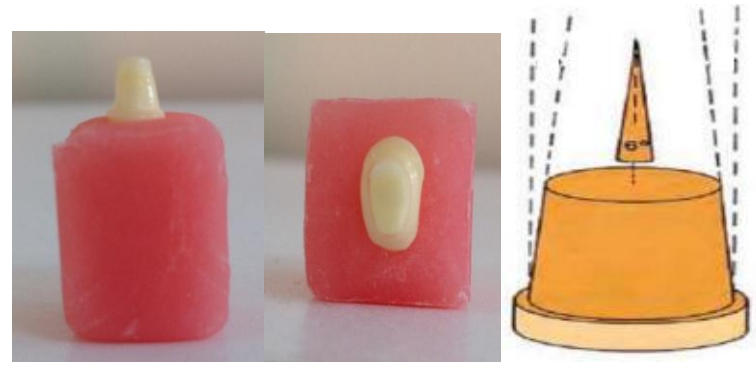

Şekil 1. Diş preparasyonu

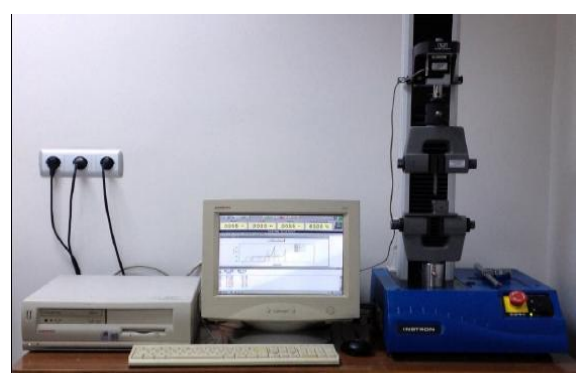

Şekil 2. Instron test cihazı

Çalışmada elde edilen bulgular değerlendirilirken, istatistiksel analizler için SPSS (Statistical Package for Social Sciences) IBS 20.00 istatistik paket programı kullanıldı. Çalışma verileri değerlendirilirken gruplar arası ortalamaların karşılaştırılmasında Çift Yönlü Varyans Analizi (TwoWay ANOVA) testi ve Post Hoc çoklu karşılaştırma testlerinden LSD testi kullanıldı.

\section{BULGULAR}

Üç farklı güdük, iki farklı solüsyon kullanılarak simante edilen ve edilmeyen Zirkon alt yapıların kırılma dayanımının ortalama değerleri, standart sapmaları, minimum ve maksimum değerleri Tablo 1'de gösterilmiştir. 
Tablo 1. Farklı güdük, bekletme ortamı ve siman durumuna göre Zirkon alt yapıların kırıma dayanım değerleri $(\mathrm{N})$

\begin{tabular}{|c|c|c|c|c|c|c|}
\hline : & 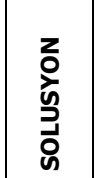 & 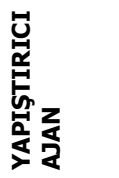 & 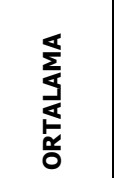 & $\begin{array}{l}\text { STAND } \\
\text { ART } \\
\text { SAPMA }\end{array}$ & $\sum_{\frac{1}{\Sigma}}^{\Sigma}$ & $\begin{array}{l}\Sigma \\
\sum \\
\frac{\Sigma}{y} \\
\frac{\Sigma}{\Sigma}\end{array}$ \\
\hline \multirow{4}{*}{$\sum_{\text {点 }}^{z}$} & \multirow{2}{*}{$\begin{array}{l}\text { Distile } \\
\text { Su }\end{array}$} & Simanlı & 5185,75 & 1019,24 & 4120 & 6217 \\
\hline & & Simansız & 3518 & 613,68 & 2733 & 4113 \\
\hline & \multirow{2}{*}{ Kola } & Simanlı & 6395,25 & 1892,20 & 3872 & 8420 \\
\hline & & Simansız & 3273,60 & 1565,43 & 2135 & 5865 \\
\hline \multirow{4}{*}{ 站 } & \multirow{2}{*}{$\begin{array}{l}\text { Distile } \\
\text { Su }\end{array}$} & Simanlı & 4530,80 & 1370,25 & 3247 & 6680 \\
\hline & & Simansız & 3444 & 1497,12 & 1477 & 4832 \\
\hline & \multirow{2}{*}{ Kola } & Simanlı & 4595,80 & 837,44 & 3451 & 5353 \\
\hline & & Simansız & 2843 & 867,75 & 2094 & 4327 \\
\hline \multirow{4}{*}{ 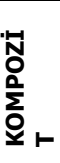 } & \multirow{2}{*}{$\begin{array}{l}\text { Distile } \\
\text { Su }\end{array}$} & Simanlı & 3959,40 & 1095,78 & 2558 & 5231 \\
\hline & & Simansız & 2242,80 & 538,32 & 1364 & 2727 \\
\hline & \multirow{2}{*}{ Kola } & Simanlı & 3860,40 & 1073,37 & 2850 & 5599 \\
\hline & & Simansız & 2288,60 & 814,21 & 1072 & 3349 \\
\hline
\end{tabular}

Güdük materyallerinin kırılma dayanımı değerleri arasındaki fark istatistiksel olarak anlamlı bulundu $(p<0,05)$. LSD çoklu karşılaştırma testine göre metal güdükle kompozit güdük arasındaki fark istatistiksel olarak anlamlıyen $(p<0,05)$, dentin güdükle arasındaki fark istatistiksel olarak anlamlı değildir $(p>0,05)$. Kompozit ve dentin güdük arasındaki fark istatistiksel olarak anlamlı bulundu $(p<0,001)$. Güdük çeşidine göre Zirkon alt yapı kırıma dayanımı değeri en yüksek dentinde, en düşük değer ise kompozitte bulundu.

Simante edilmiş grupla simante edilmemiş grup arasındaki farklılık istatistiksel olarak anlamlı bulundu $(p<0,001)$. Simante edilen alt yapılar tüm gruplarda en yüksek kırıma dayanımı gösterdi $(6395,25-3860,40$ $\mathrm{N})$.

Farklı solüsyonlara konulmuş gruplar arasında istatistiksel açıdan anlamlı fark bulunmadı $(p>0,05)$ (Şekil 1,2). Sadece distile suda bekletilen metal güdüğün simanlı ve simansız örneklerinin kırılma dirençleri arasındaki fark istatistiksel olarak anlamlıdır $(p<0,05)$.

Farklı güdük, bekleme ortamı ve yapıştıııı ajana göre Zirkon alt yapıların ortalama kırıma dayanımı değeri en yüksek kolada bekletilen, simanla yapıştııımış dentin güdük üzerinde; en düşük değeri ise distile suda bekletilen, simanla yapıştııımamış kompozit güdük üzerinde gösterdi. Kırılma dayanımı değerleri $(6395,25 \mathrm{~N}$ ile 2242,80 N) değerleri arasında değişmektedir.

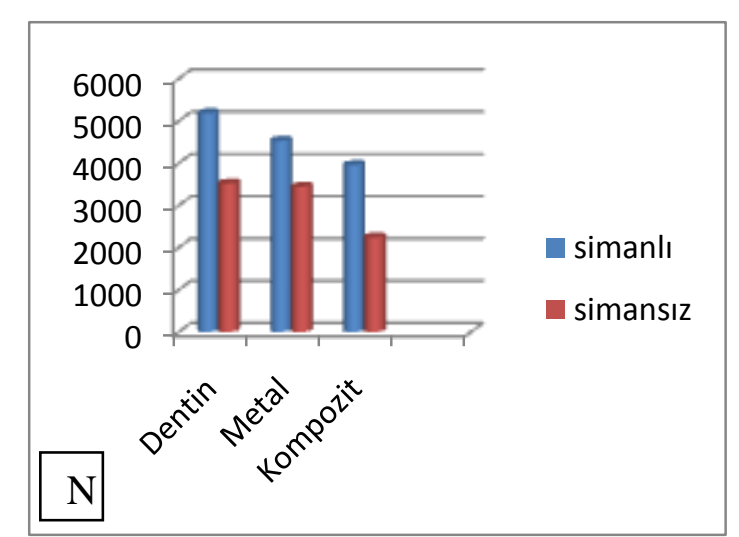

Şekil 1. Distile suda bekletilen değişik güdük materyalleri üzerindeki simante ve simante edilmemiş zirkonyum alt yapıların kırılma dayanımına ait değerler

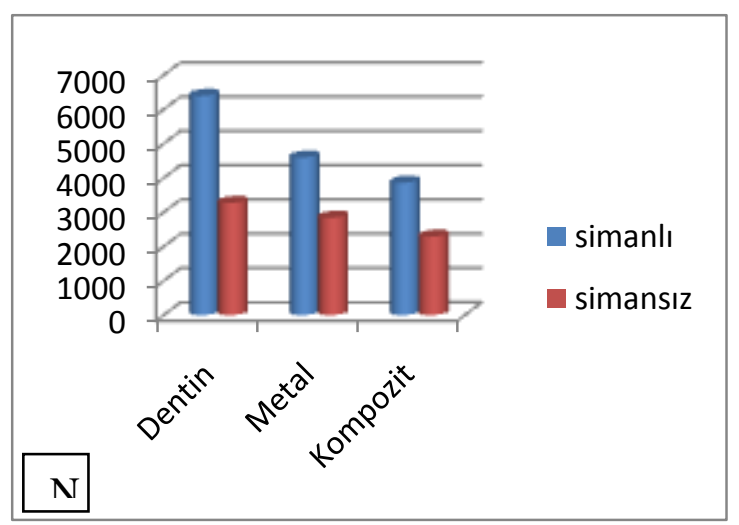

Şekil 2. Kolada bekletilen değişik güdük materyalleri üzerindeki simante ve simante edilmemiş zirkonyum alt yapıların kırıma dayanımına ait değerler

\section{TARTIŞMA}

Bu çalışmada farklı elastik modülüne sahip güdük materyaller üzerinde hazırlanan Zirkon alt yapıların kırılma direnci üzerinde, güdük materyali, saklama ortamı ve simanın etkisi incelendi.

Günümüzde estetik restorasyonlara duyulan gereksinim metal desteksiz seramiklerin gelişimini sağlamışır. Yakın tarihe kadar, tam seramik sistemlerin kullanımı sadece anterior dişler ile sınırlandırılırken, güçlendirilmiş seramik sistemlerinin geliştirilmesiyle günümüzde posterior dişlerde de uygulama alanı bulmuştur. En son geliştirilen yitriyum ile stabilize edilmiş tetragonal zirkonya polikristalleri 
(Y-TZP) yüksek dayanıklılığı ve biyouyumluluğu sayesinde yaygın olarak kullanılmaya başlanmıştır. ${ }^{26-29}$

Tam seramik sistemlerinin kırılma dayanımı üzerine çalışan araştırıcılar; bar, çubuk ve disk örnekler kullanılarak yapılan kırılma testleri yerine, porselen veneer kuronların morfolojisine yakın olan örnekler kullanılması gerektiğini bildirmişlerdir. ${ }^{30-32} \mathrm{Bu}$ kaynakların ışığı altında çalışmamızda kliniği simüle edebilmek için anatomik formda hazırlanan ${ }^{33}$, standardize edilmiş Zirkon alt yapı kullanılmıştır.

Bilgisayar destekli tasarım/bilgisayar destekli üretim (CAD/CAM) teknolojisi diş hekimleri arasında etkin şekilde kullanılan yeni tedavi modelidir. ${ }^{34}$ Sistemin temeli; çok hassas bir freze makinesinin, bilgisayar yazıımı ile çalıştırılarak seramik, kompozit veya metal bloklardan kuronlar, köprüler ve sabit protez alt yapıları üretmesi esasına dayanır. ${ }^{35}$ CAD/CAM sayesinde üretilen restorasyonlarda hep aynı kalite standardı yakalanabilmekte ve hastaya uygun başarılı restorasyonlar hazırlanabilmektedir. ${ }^{36}$ Bu çalışmada da tam seramiklerin alt yapılarında uniform kalınlık elde etmek için CAD/CAM sistemi kullanılmıştır.

Klinik çalışmalar bir materyalin etkinliğinin değerlendirilmesinde en güvenilir yöntem olmasına rağmen, bu çalışmaların gerçekleştirilmesi, çalışmaya dahil edilen hastaların takibi zordur ve uzun zaman alır. Bu yüzden çalışmamız in vitro ortamda gerçekleştirilmiştir. ${ }^{37}$ Tam seramik kuronlarda kırılma dayanımının değerlendirildiği çoğu çalışmada güdük materyali olarak metal ${ }^{21,38,39}$, pirinç ${ }^{40,41}$, epoksi rezin ${ }^{21,38,42,43}$ ve dentin ${ }^{21,44}$ kullanılmıştır. Bu çalışmada da bu amaçla klinik ortamı taklit edebilmek ve standardizasyonu sağlayabilmek için dentinin elastik modülüne yakın güdük materyali arayışına girilmiştir.

Elastik modül bir malzemenin sertliği hakkında bilgi verir. Materyalin elastik modülü yüksekse belirli bir yük altında daha az deforme olur; kuron iç yüzeyine daha az makaslama kuvveti iletir. Bu nedenle güdük materyalinin elastik modülü kurona desteklik için bir ölçüt olarak kullanılabilir ve kuronun kırılmasını engelleyebilir. ${ }^{40,45}$ Scherrer ve ark. ${ }^{46}$ yaptıkları çalışmada kuronu destekleyen güdüğün elastik modülü arttıkça tam seramik kuronların kırılma dayanımı değerlerinin de arttığını bulmuşlardır. Yücel ve ark. ${ }^{20}$ güdük materyallerinin tam seramik materyallerin kırılma dayanımına etkisini inceledikleri çalışmada, elastik modül değerlerini büyükten küçüğe; metal> pirinç> dentin> epoksi rezin şeklinde olduğunu bildirmişlerdir.
Sağsöz ${ }^{21}$ farklı güdük materyalleri üzerine simante edilen kuronların ortalama kırılma dirençlerini incelediği tez çalışmasında, güdüklerin elastik modül değerlerini büyükten küçüğe; metal> epoksi rezin> dentin olarak bulmuştur.

Bu çalışmada, zirkon alt yapılar dentin güdük üzerinde en yüksek kırılma değeri göstermiştir. Bunu metal ve kompozit güdük üzerindeki zirkon alt yapılar takip etmiştir.

In vitro çalışmalarda kuronların üretim teknikleri, yüzey bitim işlemleri ${ }^{47}$, yapıştırıcı siman, kırıma dayanımı testi uygulanmadan önceki saklama koşullarının ${ }^{31,48-50}$ tam seramik kuronların kırılma direncini ve mekanik özelliklerini etkilediği görülmüştür. Sabit protetik restorasyonların başarısında simantasyon işlemi ve kullanılan yapıştırma simanı önemli rol oynar. Bu restorasyonların başarısızlık nedenlerinin değerlendirildiği çalışmada; simantasyon işlemine bağı kuron retansiyonunun kaybı en önde gelen sebeplerden birisi olarak belirtilmiştir. ${ }^{51}$ Yüksek dayanımlı seramiklerde kırılmaya bağlı başarısızıı oranı \% 2,3 -8 arasındadır. $\mathrm{Bu}$ nedenle yapıştırma simanının seramik yüzeyi ile tam bir bağlantı oluşturması restorasyonun başarısında çok önemli bir etkendir. ${ }^{52}$ Bazı araştırmacılar yaptıkları çalışmalarında, simante edilmemiş örneklerin simante edilmiş olanlardan daha düşük kırılma dayanımı gösterdiğini bildirmişlerdir. ${ }^{20,53}$

Sakoguchi ve ark. ${ }^{54}$ epoksi rezin, metal ve kompozit güdük kullanarak iki farklı kompozit rezin kuronun kırılma dayanımını inceledikleri çalışmalarında; kompozit rezin güdük üzerine simante edilen kuronlar metal güdük üzerine simante edilen kuronlardan daha fazla kırılma dayanımı gösterdiği sonucuna varmışlardır. Bindl ve ark. ${ }^{55}$ simante edilmiş seramik kuronların kırılma dayanımını materyallerin elastik modülünün etkilediğini; hibrit kompozit rezinin elastik modülünün dentinin elastik modülüne benzer olduğu sonucuna vardılar.

Çalışmamızın sonucunda siman ile yapıştırıımış örneklerimizin kırıma dayanımı 4680,57 N; siman kullanılmayan örneklerimizin kırıma dayanımı ise 2914,89 N bulunmuştur. Simante edilen örneklerin kırılma dayanımı değeri simante edilmeyenlerin kırılma dayanımı değerinden yüksek bulunmuştur ve çalışmaları destekler niteliktedir.

Tam seramik sistemlerde nemli ve kuru ortamın kırılma dayanımına etkisinin araştırıldığı çalışmalarda nemli ortamın kuron içinde gözenek oluşturup küçük

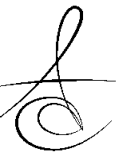


çatlakların yayılmasına neden olacağını bildirmişlerdir. ${ }^{56,57}$ Ancak literatürde asidik solüsyonların etkisinin olup olmadığını araştıran çalışma bulunmamaktadır. Asidik ortamın etkisinin araştırıldığı çalışmamızda farklı solüsyonlar zirkon alt yapılarda kırılma dayanımı açısından herhangi bir farklılık oluşturmamıştır. İstatistiksel olarak farklı kırılma direncinin bulunmaması simanın çözünmemesinden ve bekletme süresinden kaynaklı olabileceği düşünülmektedir.

Bağlanma dayanımı, kırıma dayanımı, mikrosızıntı ya da marjinal adaptasyon gibi laboratuvar testleri dental materyallerin kısa sürede değerlendirilmesini sağlarlar ve materyallerin klinikte kullanımı ile ilgili bir ön bilgi verirler. ${ }^{44,58-60}$ Restoratif materyallerin kırılma dayanımını ölçme işleminin standart bir prosedürü yoktur. Restoratif sistemlerin kırılma direnci ile ilgili yapılan in vitro çalışmalar bu materyallerin yüke dayanma kapasiteleri hakkında fikir edinmemizi sağlayarak, klinik çalışmalar için temel oluşturmaktadırlar. ${ }^{61} \mathrm{Bu}$ test inley, kuron, köprü gibi örneklerin kuvvet altında kırılmalarını sağlayarak yapılır. Ancak bu test metodunda her çalışma farklı tasarlanabileceği için çalışma sonuçlarını birbirleriyle karşılaştırmak oldukça zordur. $^{62}$

Birçok araştırmacı dental porselenlerin kırılma direnci üzerine yaptığı çalışmalarda farklı sonuçlar ortaya çıkmasını test cihazındaki yükleme hızına bağlamıştır. Çalışmalara göre yükleme hızı arttıkça, siman ve restorasyon içerisindeki çatlak oluşumu ve çatlak ilerlemesi için yeterli zaman bırakılmaması nedeniyle hatalı veriler ortaya çıkacağı iddia edilmiştir. ${ }^{31,32,63,64}$ Bu sebeple, araştırmamızda yükleme hızı 0,5 mm/dk. olarak uygulanmıştır.

Çalışmamızda kurmuş olduğumuz hipotezimiz simanın etkili olması nedeniyle bu yönü ile kabul edilirken, güdük materyalleri ve ortam açısından değerlendirildiğinde reddedilmiştir.

\section{SONUÇLAR}

Mevcut çalışmada elde edilen bulgulardan yola çıkılarak aşağıdaki sonuçlara ulaşılmıştır:

1. Zirkon alt yapıların ortalama kırıma dayanımı değeri en yüksek kolada bekletilen, simanla yapıştırımış dentin güdük üzerindeki grupta görülürken $(6395,2 \mathrm{~N})$; en düşük değer $(2242,8 \mathrm{~N})$ ise distile suda bekletilen, simanla yapıştırılmamış kompozit güdük üzerindeki örneklerde elde edilmiştir.

2. Dentin güdükler üzerinde en yüksek kırılma dayanımı değeri $(4515,5 \pm 1809,9 \mathrm{~N})$ görülürken, bunu metal $(3853,4 \pm 1323,5 \mathrm{~N})$ ve kompozit güdükler $(3087,8 \pm 1186,9 \mathrm{~N})$ üzerindeki zirkon alt yapılar takip etmiştir.

Simante edilmiş zirkon alt yapıların kırılma direnci, simante edilmeyenlerden daha yüksek bulunmuştur. Simante edilmemiş zirkon alt yapıların ortalama kırılma dayanımı değeri en yüksek dentin güdükler için $(3382,2 \mathrm{~N})$ tespit edilirken, simante edilmiş olan grupta da en yüksek değer yine dentin güdükler için $(5790,5 \mathrm{~N})$ bulunmuştur.

\section{KAYNAKLAR}

1. Casson AM, Glyn Jones JC, Youngson CC. The effect of luting media on fracture resistance of a flame sprayed all-ceramic crown. J Dent 2001; 29: 53944.

2. Sjogren G, Sletten G, Dahl JE. Cytotoxicity of dental alloys, metals, and ceramics assessed by millipore filter, agar overlay, and MTT tests. J Prosthet Dent 2000; 84: 229-36.

3. Siervo S, Pampalone A, Siervo P. Where is the gap? Machinable ceramic systems and conventional laboratory restorations at a glance. Quintessence Int 1994; 25: 773-9.

4. Guazzato M, Albakry M, Ringer SP, Swain MV. Strength, fracture toughness and microstructure of a selection of all-ceramic materials. Part 1.Pressable and alümina glass -infiltrated ceramics. Dent Mater 2004; 20:441-8.

5. Yilmaz H, Aydin C, Gul BE. Flexural strength and fracture toughness of dental core ceramics. J Prosthet Dent 2007; 98:120-8.

6. Powers JM, Sakaguchi RL. Craig's Restorative Dental Materials. 12. Edition. Mosby, St. Louis. 2006; 32, 455.

7. Sun $T$, Zhou S, Lai R, Liu R, Ma S, Zhou $Z$, Longquan S. Load-bearing capacity and the recommended thickness of dental monolithic zirconia single crowns. J Mech Behav Biomed Mater 2014; 35:93-101.

8. Jeong SM, Ludwig K, Kern M. Investigation of the fracture resistance of three types of zirconia posts in all-ceramic postand- core restorations. Int J Prosthodont 2002; 15:154-8. 
9. Denry I, Kelly JR. State of the art of zirconia for dental applications. Dent Mater 2008;24:299-307.

10. Strub JR, Rekow ED, Witkowski S. Computer-aided design and fabrication of dental restorations. Current Systems and Future Possibilities, J Am Dent Assoc 2006;137:1289-96.

11. Jedynakiewicz N.M, Martin N. CEREC: science, research, and clinical application The Compendium of Continuing Education in Dentistry, 22 (2001), pp. 7-13.

12.Liu PR. A panorama of dental CAD/CAM restorative systems. Compend Contin Educ Dent. 2005; 26:507-8, 510, 2 .

13. Pjetursson Be, Saıler I, Zwahlen M, Hammerle Ch. A systematic review of the survival and complication rates of all-ceramic and metalceramic reconstructions after an observation period of at least 3 years. Part I: single crowns. Clin Oral Implants Res 2007; 18 (Suppl 3): 73-85.

14. Rosenstiel SF, Land MF, Crispin BJ. Dental luting agents: a review of the current literature. J Prosthet Dent. 1998; 80:280-301.

15. Zeng $K$, Odén A, Rowcliffe D. Evaluation of mechanical properties of dental ceramic core materials in combination with porcelains.Int J Prosthodont.1998; 11: 183-9.

16. Yoshinari $M$, Dérand $T$. Fracture strength of allceramic crowns. Int J Prosthodont 1994;7:329-38.

17. Scherrer SS, de Rijk WG. The fracture resistance of allceramic crowns on supporting structures with different elastic moduli. Int J Prosthodont. 1993;6:462-7.

18. Cho L, Song H, Koak J, Heo S. Marginal accuracy and fracture strength of ceromer/fiber-reinforced composite crowns: effect of variations in preparation design. J Prosthet Dent.2002; 88:38895.

19. Potiket N, Chiche G, Finger IM. In vitro fracture strength of teeth restored with different all-ceramic crown systems. . J Prosthet Dent 2004; 92: 491-5.

20. Yucel MT, Yondem I, Aykent F, Eraslan O. Influence of the supporting die structures on the fracture strength of all-ceramic materials. Clin Oral Investig 2012;16:1105-10.

21.Polat Sağsöz N. Farklı siman aralıklarında hazırlanan CAD/CAM monolitik kuronların kırıma direncinin değerlendirilmesi. Protetik Diş Tedavisi. Doktora Tezi, Atatürk Üniversitesi Diş Hekimliği
Fakültesi, Erzurum, 2015.

22. Scherrer SS, de Rijk WG. The fracture resistance of allceramic crowns on supporting structures with different elastic moduli. Int ] Prosthodont.1993; 6:462-7.

23.Aksoy İ, Varol S, Özkan Y. Zirkonyum restorasyonların simantasyonu. Atatürk Üniv. Diş Hek. Fak. Derg. Cilt: 6,Yıl: 2012, Sayfa : 124-31.

24. Burke FJ. Fracture resistance of teeth restored with dentin-bonded crowns constructed in a leucite-reinforced ceramic. Dent Mater 1999; 15: 359-62.

25. Burke FJ, Watts DC. Effect of differing resin luting systems on fracture resistance of teeth restored with dentin-bonded crowns. Quintessence Int 1998; 29:21-7.

26. Deville S, Chevalier J, Gremillard L. Influence of surface finish and residual stresses on the ageing sensitivity of biomedical grade zirconia. Biomaterials 2006; 27: 2186-92.

27. Covacci V, Bruzzese N, Maccauro G, Andreassi C, Ricci GA, Piconi C. In vitro evaluation of the mutagenic and carcinogenic power of high purity zirconia ceramic. Biomaterials.1999; 20: 371- 6.

28. Saldana JM, Ramirez HB, Vigueras DJ, Iga T, Schneider GA. Mechanical properties and lowtemperature aging of tetragonal zirconia polycrystals processed by hot isostatic pressing. J Mater Res 2003; 18.

29. Kosmac T, Oblac C, Jevnikar P, Funduk N, Marion L. Strength and reliability of surface treated Y-TZP dental ceramics. J Biomed Mater Res Appl Biomater 2000; 53: 304-13.

30.Chai J, Takahashi Y, Sulaiman F, Chong K, Lautenschlager EP. Probability of fracture of allceramic crowns. Int J Prosthodont 2000;13:4204.

31.Strub JR, Beschnidt SM. Fracture strength of 5 different all-ceramic crown systems. Int J Prosthodont 1998; 11:602-9.

32. Yoshinari $M$, Derand $T$. Fracture strength of allceramic crowns. Int J Prosthodont 1994; 7:32938.

33.Tinschert J, Zwez D, Marx R, Anusavice KJ. Structural reliability of alümina-,feldspar-,leucite,mica- and zirconia based ceramics. Journal of Dentistry 2000; 28:529-35. 
34. Jedynakiewicz NM, Martin N: CEREC: science, research and clinical application. Compend Contin Edu Dent 2001; 22:7-13.

35. Heffernan MJ, Aquilino SA, Diaz-Arnold AM, Haselton DR, Stanford CM, Vargas MA. Relative translucency of six all-ceramic systems. Part 2: core and veneer materials. J Prosthet Dent 2002; 88:10-5.

36. Karaalioğlu OF, Duymuş Yeşil Z. Diş Hekimliğinde Uygulanan CAD/CAM sistemleri. Atatürk Üniv Diş Hek Fak Derg 2008; 18:25-32.

37. Rosentritt $M$, Plein $T$, Kolbeck $C$, et al: In vitro fracture force and marginal adaptation of ceramic crowns fixed on natural and artificial teeth. Int J Prosthodont 2000; 13:387-91.

38. Hwang JW, Yang JH.Fracture strength of copymilled and conventional In-Ceram crowns. J Oral Rehabil.2001;28:678-83.

39.Akesson J, Sundh A, Sjögren G. Fracture resistance of all ceramic crowns placed on a preparation with a slice-formed finishing line. J Oral Rehabil 2009; 36:516-23.

40. Lee SK, Wilson PR. Fracture strength of all-ceramic crowns with varying core elastic moduli. Aust Dent J 2000; 45:103-7.

41. Webber B, McDonald A, Knowles J. An in vitro study of the compressive load at fracture of Procera AllCeram crowns with varying thickness of veneer porcelain. J Prosthet Dent 2003; 89:15460.

42. Wood KC, Berzins DW, Luo Q, Thompson GA, Toth JM, Nagy WW. Resistance to fracture of two allceramic crown materials following endodontic access. J Prosthet Dent 2006; 95:33-41.

43. Zahran M, El-Mowafy O, TamL, Watson PA, Finer Y. Fracture strength and fatigue resistance of allceramic molar crowns manufactured with CAD/CAM technology. J Prosthodont 2008; 17: $370-7$.

44. Preuss A, Rosentritt $M$, Frankenberger R, Beuer $F$, Naumann $M$. Influence of type of luting cement used with all-ceramic crowns on load capability of post-restored endodontically treated maxillary central incisors. Clin Oral Investig.2008; 12:151-6.

45. Phillips RW. Skinner's science of dental materials, 9th edn. Saunders, Philadelphia.1991

46. Scherrer SS, de Rijk WG. The fracture resistance of all ceramic crowns on supporting structures with different elastic moduli. Int J Prosthodont 1993; 6: 462-7.

47. Chen HY, Hickel R, Setcos JC, Kunzelmann KH. Effects of surface finish and fatigue testing on the fracture strength of CAD-CAM and pressed ceramic crowns. J Prosthet Dent 1999; 82:468-75.

48. Attia A, Kern M. Influence of cyclic loading and luting agents on the fracture load of two allceramic crown systems. J Prosthet Dent 2004; 92: 551-6.

49. Cho L, Choi J, Yi YJ, Park CJ. Effect of finish line variants on marginal accuracy and fracture strength of ceramic optimized polymer/fiber reinforced composite crowns. J Prosthet Dent 2004; 91:554-60.

50. MormannW, Bindl A, Luthy $H$, Rathke A. Effects of preparation and luting system on all-ceramic computer-generated crowns. Int J Comput Dent 1998; 11:333-9.

51. Walton JN, Gardner FM, Agar JR. A survey of crown and fixed partial denture failures: length of service and reasons for replacement. J Prosthet Dent 1986;56:416-21.

52. Libby G, Arcuri MR, La Velle WE, Hel L. Longevity of fixed partial dentures. J Prosthet Dent 1997; 78: 127-31.

53. Prakki A, Cilli R, Da Costa AU, Gonçalves SE, Mondelli RF, Pereira JC.Effect of Resin Luting Film Thickness on Fracture Resistance of a Ceramic Cemented to Dentin. J Prosthodont 2007; 16: $172-8$

54. Sakoguchi K, Minami H, Suzuki S, Tanaka T. Evaluation of fracture resistance of indirect composite resin crowns by cyclic impact test: influence of crown and abutment materials. Dent Mater ] 2013; 32:433-40.

55. Bindl A, Luthy $H$, Mormann WH. Strength and fracture pattern of monolithic CAD/CAM-generated posterior crowns. Dental materials : official publication of the Academy of Dental Materials 2006; 22:29-36.

56. J.R. Kelly. Clinically relevant approach to failure testing of all-ceramic Restorations.J Prosthet Dent 1999; 81:652-61

57. L.C. Sobrinho, M.J. Cattell, R.H. Glover, J.C. Knowles. Investigation of the dry and wet fatigue properties of three all-ceramic crown Systems. Int J Prosthodont 1998; 11: 255-62.

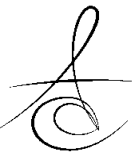


58. Sakaguchi RL, Powers JM. Craig's Restorative Dental Materials. 13th ed. Philadelphia, Mosby, 2012

59. Braga RR, Meira JB, Boaro LC, Xavier TA. Adhesion to tooth structure: a critical review of "macro" test methods. Dental Materials: Official Publication of the Academy of Dental Materials 2010; 26: 38-49.

60. Armstrong S, Geraldeli S, Maia R, Raposo LH, Soares CJ, Yamagawa J. Adhesion to tooth structure: a critical review of "micro" bond strength test methods. Dental Materials : Official Publication of the Academy of Dental Materials 2010; 26: 50-62.

61. Ku CW, Park SW, Yang HS. Comparison of the fracture strengthsof metal-ceramic crowns and three ceromer crowns. J Prosthet Dent 2002, 88: 170-5.

62. Sadighpour L,Geramipanah F,Raeesi B.In Vitro Mechanical Tests for Modern Dental Ceramics. Journal of Dentistry, Tehran Universityof Medical Sciences 2006; 3:143-52.

63. Philp GK, Brukl CE. Compressive strengths of conventional, twin foil, and all-ceramic crowns. J Prosthet Dent 1984; 52: 215-20.

64. White SN, Caputo AA, Vidjak FM, Seghi RR. Moduli of rupture of layered dental ceramics. Dent Mater $1994 ; 10: 52-8$.

\author{
Yazışma Adresi: \\ Dr. Özlem ÖZBAYRAM \\ Yeni mahalle \\ 76 sok. no: $10 / 3$ \\ Nazilli/AYDIN \\ TIf: 5544200442 \\ ozlem_ozbayram@hotmail.com
}

